\title{
Article
}

\section{How do high-level youth soccer players approach and solve game problems? The role of strategic understanding}

Price, Amy, Collins, Dave and Stoszkowski, John Robert Available at http://clok.uclan.ac.uk/39081/

Price, Amy, Collins, Dave and Stoszkowski, John Robert ORCID: 0000-00021968-5770 (2021) How do high-level youth soccer players approach and solve game problems? The role of strategic understanding. Physical Education and Sport Pedagogy . ISSN 1740-8989

It is advisable to refer to the publisher's version if you intend to cite from the work. http://dx.doi.org/10.1080/17408989.2021.1967307

For more information about UCLan's research in this area go to http://www.uclan.ac.uk/researchgroups/ and search for <name of research Group>.

For information about Research generally at UCLan please go to http://www.uclan.ac.uk/research/

All outputs in CLoK are protected by Intellectual Property Rights law, including Copyright law. Copyright, IPR and Moral Rights for the works on this site are retained by the individual authors and/or other copyright owners. Terms and conditions for use of this material are defined in the policies page.

\section{CLoK}

Central Lancashire online Knowledge www.clok.uclan.ac.uk

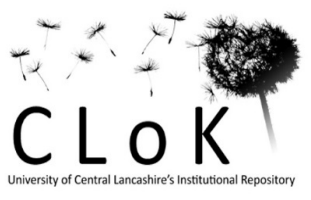


Running head: APPROACHING AND SOLVING GAME PROBLEMS

6 How do high-level youth soccer players approach and solve game problems? The role of 7 strategic understanding

8

Date of final accepted manuscript: $17^{\text {th }}$ Jul 2021

Word count: 8776

11

Corresponding Author: Amy Price, University of Edinburgh amyprice10@yahoo.co.uk Dave Collins, University of Edinburgh \& Grey Matters Ltd dave@greymattersuk.com John Stoszkowski, University of Central Lancashire jrstoszkowski@uclan.ac.uk 
Running head: APPROACHING AND SOLVING GAME PROBLEMS

Abstract

Background: Invasion team sports such as soccer require teams and individual players to understand the game and problem solve. One aspect of problem solving that has recently been more prominent in team sport literature is the role of metacognition.

Purpose: The purpose of the current study was to examine how high-level youth soccer players approach and solve problems, with a particular focus on the role of strategic understanding. We were interested in the range and sophistication of cognitive strategy and process used by players when tackling game problems. Also, the ways in which they plan, monitor and evaluate how they approach and solve problems.

Methods: Eighteen high-level youth soccer players took part in semi-structured interviews which adopted Applied Cognitive Task Analysis (ACTA) protocol. Interview data were analysed using deductive content analysis to distinguish use of cognitive and metacognitive thinking.

Findings: Results showed that players displayed a range of cognitive processes when solving problems, but more sophisticated processes were least employed. Furthermore, there was little evidence of a strategic approach to problem solving.

Conclusions: Players would benefit from practicing their problem-solving skills. Coaches should pay due attention to 'what' and 'how' players think when problem solving. Coach education might consider how to educate coaches to better equip players to solve stubborn game problems. One possibility is to present coaches with methods which make player thinking overt. 
Running head: APPROACHING AND SOLVING GAME PROBLEMS

How do high-level youth soccer players approach and solve game problems? The role of strategic understanding

\section{Introduction}

Within team sports such as soccer, the ability to solve problems in the game itself is an important skill for any player, subgroup of players, or team (Grehaigne and Godbout, 1995; Almond, 2015; Pill and Hyndman, 2018). Indeed, good problem-solving skills in soccer have formerly been associated with 'thinking players' (Australian Sports Commission 1996; den Duyn 1997), have high 'game intelligence' (Wein, 2004; Stratton, et al. 2004) or are 'good learners' (Price et al. 2017). Notably these terms describe players who are able to outwit opponents on an individual and/or team level, in situations unique to the circumstances of each particular game. Solving problems is therefore a vital feature of game play and one that both academic researchers and coaches recognise as being central to the development of deeper levels of game understanding (Price, et al. 2020). The challenge for coaches is to understand how this is achieved as an essential precursor to optimising its development through practice.

One key element of effective problem solving in sport is the appropriate use of knowledge during decision making. Earlier research in this domain has examined the differences between expert and novice games players to ascertain the impact of declarative knowledge (knowing about the sport) and procedural knowledge (knowing how to perform the sport) (Williams and Davids, 1995; Nevett and French, 1997; McPherson, 1999, 2000). Typically, these studies have found that players with greater declarative knowledge show an increased potential for skill development and execution, and they are more likely to 'explore the boundaries of their action capabilities' (Ashford, Abraham, and Poolton 2020, 3). More recent research examining the role of declarative knowledge during decision making concurs and indicates how players with a deeper sport knowledge are more capable of understanding why (and why not) a decision would be effective (Kannekens, Elferink-Gemser, and Visscher 
Running head: APPROACHING AND SOLVING GAME PROBLEMS

2009, 2011; Johnstone and Morrison, 2016). This suggests that skilled performers are both quicker and more efficient at accessing knowledge about the game to inform how to execute their next action. Most recently, investigation of the visual search strategies of skilled performers has shown them more able to effectively prioritise and locate important information to inform their decisions (Roca, Ford, and Memmert 2020). Consequently, the visual search strategies of skilled performers provide greater opportunity to anticipate and act effectively when under strong time constraints, such as during unique game situations (Collins, Collins, and Carson 2021). A recognition primed decision-making approach to training (RPDM; Klein, 2008) where visual stimuli are repeatedly presented, has therefore been proposed to enhance the development of anticipation skills. For example, Lex et al. (2015) found that experienced soccer players possess a more structured memory of team tactics and require less time and information to locate suitable options.

Parallel strands of research have examined the role of metacognition. Metacognitive thinking has been defined by Flavell (1979) as thinking about one's thinking and in a sporting context, metacognition has been broadly described as cognition about thoughts and feelings (MacIntytre et al. 2014). Seminal work on this topic has referred to metacognition as involving problem solving skills such as predicting, checking, monitoring, testing and controlling deliberate attempts to learn (Brown, 1987). Importantly, empirical evidence indicates that metacognition can be taught in the school classroom, with children as young as eight years old capable of developing (Jacobs and Paris, 1987; Veenman and Spanns, 2005; Wang et al. 2021; Weil et al. 2013). Indeed, further empirical research suggests children younger than eight years old have the capability to think on a meta-level (Pino-Pasternak and Whitebread, 2010). Evidence pertaining to the metacognitive capabilities of children is important for coaches to recognise, suggesting that age is no reason to disregard the role of metacognition when problem solving in team sport. Nonetheless, how information is processed and the ways in which 
Running head: APPROACHING AND SOLVING GAME PROBLEMS

99 declarative and procedural knowledge structures interact during the problem-solving process

100 is complex and remains unclear.

\section{The relationship between problem solving and decision making}

102 Making decisions is a part of problem solving and in dynamic team sports such as

103 soccer, there is almost never a moment when players are not required to make decisions about

104 a problem to be solved. To date, a range of existing literature has focussed on decision making

105 in team sport and its associated elements, such as perception, attention and anticipation

106 (Vaeyens et al. 2011; Roca, Williams, and Ford 2012; Roca, Ford and Memmert 2018). In

107 comparison, however, minimal attention has been paid to the problem-solving process and how

108 this works in combination with decision making. For example, the selection of an appropriate

109 action in invasion team sport has been assessed in time pressured situations (Kinrade, Jackson,

110 and Ashford 2015), as has the 'thinking through' of contextual information during the decision-

111 making process and its impact on how and why players and teams might change their plan of

112 action (Maquet and Kragba, 2015). Importantly, however, it seems safe to suggest that even

113 expert players will not solve every problem first time (especially when playing against other

114 expert players). This is where further research is required to establish the mechanisms of player

115 thinking as a problem becomes more stubborn, or otherwise, when the difficulty of a problem

116 increases. Notwithstanding these exceptions, coaches are left with a void of information about

117 this critical aspect of team games, an important omission which deserves attention.

\section{Cognitive process and strategy used for problem solving}

119 In the context of soccer, Price et al. (2020) built upon Weinstein and Van Mater Stone's

120 (1993) framework for knowledge sources in an attempt to measure and apprehend the extent

121 to which players think strategically when problem solving. In this framework, the player is

122 required to understand several interacting factors; 
Running head: APPROACHING AND SOLVING GAME PROBLEMS

123

124

125

126

127

128

- Themselves (i.e., how do I learn best, what motivates me, what are my individual action capabilities)

- Players involved (i.e., individual and collective action capabilities, preferred team playing style)

- Problem (e.g., the opponent is creating goal scoring chances by playing through our midfield area)

- Goal (e.g., we aim to compact the central areas to deny the opposition playing through our midfield)

- Solution (e.g., our forwards will position themselves more narrowly when possession is lost).

Factors are combined through a cognitive strategy to monitor whether progress is being made toward solving the problem. Cognitive strategy suggests the player is actively selecting, executing, monitoring and controlling a cognitive process (e.g., I will copy the positioning of my teammate when we lose possession, until I feel confident to position myself).

Thinking on this meta-level therefore involves an ongoing learning process of planning, monitoring and evaluating how to solve the problem. Players who think metacognitively will continue this ongoing learning process until the problem is no longer a problem, or another problem takes priority (usually because of the level of severity the problem causes if left unsolved). Consequently, the purpose of the current study was to examine how high-level youth soccer players approach and solve problems, with a particular focus on the role of strategic understanding. Our primary objective was to establish the range and sophistication of cognitive strategy and process used by players when tackling game problems. We also wished to examine the ways in which players are in control of how they plan, monitor and evaluate how they approach and solve problems. Specifically, how they use knowledge of the game, 
Running head: APPROACHING AND SOLVING GAME PROBLEMS

147 knowledge of people playing the game (including themselves), and knowledge of cognitive 148 strategies.

\section{Materials and Methods}

\section{Participants}

Participants in the current study $(N=18)$ were Under 13 and Under 14 players from one professional boy's youth football academy in England. Players train three times and play one game per week against opposition boy's youth academy teams. All players were coached by UEFA (Union of European Football Associations) qualified coaches and have been coaching professional boy's youth academy football for at least five years. The heads of coaching at several professional boy's youth football academies in England were initially contacted to gauge their interest in taking part. One academy was selected based upon the head of coaching's belief in the research project aims. All players within the Under 13 and Under 14 teams were invited by the club via email to take part in the study (excluding goalkeepers due to their unique role in the team), and $85 \%$ accepted this invitation.

All 18 participants were male and reported themselves to be British. Prior to gaining informed consent from all participants and their parents/guardians, a University ethics committee approved the study, and participants and their parents/guardians were notified that they could withdraw from the study at any time.

\section{Procedures for Interviews}

All interviews took place as a one-to-one conversation between the player and first author in the club's classroom. Each interview started with a general introduction and rapport building conversation, whereby the purpose of the study was explained to players, as well as their rights and a declaration of confidentiality (White and Thomson, 1995). Discussion was 
Analysis (ACTA) 'toolkit' which involved both retrospective and prospective probes (see

Table 1). The protocol followed in each interview is detailed below:

1. Task scenario. All participants responded individually to the same exemplar football scenario (playing out from the goalkeeper), as this scenario reflected a moment of the game that was consistent within the club's coaching curriculum.

2. Knowledge audit. Each responded individually to a video clip from their most recent of two days between the competition game and the interview. Each clip was no longer than 30 seconds in duration and was selected by the Under 13 and Under 14 team coaches on the basis that the player being interviewed had clearly and obviously outwitted an opponent. Therefore, the player was deemed to have either solved a problem or made some progress in solving a problem. To confirm reliability of selected clips, the first author requested a rationale from the coaches to explain their choice of clips, and all clips were checked by the first author against the rationale. If the first author disagreed with a choice of clip, the coaching team provided an alternative.

3. Simulation. Participants responded individually to a video clip selected by the coach (again no longer than 30 seconds in duration) from the club's senior adult team during season 19/20. In the clip, a player had been clearly and obviously outwitted by an opponent. Therefore, the player had failed to solve a problem, or made weak or no progress in solving a problem. All participants did not respond to exactly the same stimuli, as the clips were determined by their own individual playing position, although the Under 13 and Under 14 team coaches were asked to select clips showing problems of equivalent complexity. To confirm reliability of the stimulus provided by the clips, processes used in the knowledge audit were repeated in the simulation, providing an internal point of comparison. 
Running head: APPROACHING AND SOLVING GAME PROBLEMS

196 Following preliminaries, interviews lasted an average of 22 minutes (range $=18-32$ minutes).

197 All verbal responses were audio recorded using a Voice Memos mobile application

198 (https://support.apple.com/en-gb/HT206775) on an Apple iPhone XS then transcribed

199 verbatim. All visual responses were screen recorded using Tactical Pad

200 (https://www.tacticalpad.com/new/), an interactive football technology application used on an

201 Apple iPad ( $7^{\text {th }}$ Generation) device.

202

203

204

205

206

207

208

209

210

211

212

213

214

215

216

217

218

219

220

\section{Data Analysis}

To move the concept of problem solving and strategic understanding toward a more specific, situational and context rich outlook (Elo and Kyngas, 2008), data were analysed deductively. To guide this process, Weinstein and Mayer's (1986) structured categorisation matrix of learning strategies was used to organize the data (see Table 2). Specifically, the deductive analysis was used to assess the extent to which views gained supported elements of understanding (cognition) and deep understanding (metacognition). In listing appropriate data extracts for each category in the matrix, the first author asked themself questions such as;

1. To what extent is rehearsal, organisation and elaboration at play?

2. To what extent is person knowledge, task knowledge and strategy knowledge at play?

3. How do cognitive processes interact?

4. How do metacognitive processes interact?

5. How do cognitive processes interact with metacognitive processes?

6. Where do any of these processes fail to interact?

7. What is suggestive of the players' confidence in his responses?

During the analysis process, some parts of the data deemed to be worthy of a higher level of consideration (Patton, 1990) were also considered at a more latent level (Bengtsson, 2016). As we were interested in uncovering underlying cognitive and metacognitive processes 


\section{Running head: APPROACHING AND SOLVING GAME PROBLEMS}

and strategies used, interpretation was at times needed in order to discover the deeper meanings of some words and phrases individuals used (cf. Bengtsson, 2016; Javadi and Zarea, 2016). For example, a common term used by all players in this study which was worthy of discovering a deeper meaning was 'checking my shoulder'. Every time this phrase appeared in data analysis categories from the matrix it was considered as a meaning unit. All meaning units were extracted as quotations and were read and re-read by the first author. Interpretation of meaning units was in context to the sentence to which it appeared, the interview protocol (task scenario, knowledge audit, simulation) and the global language of soccer. In this example, 'checking my shoulder' is widely understood in soccer as scanning. Scanning is "an active head movement where a player's face is temporarily directed away from the ball to gather information in preparation for subsequently engaging with the ball" (Gordet, et al. 2020).

Interpretating when and how players were thinking cognitively and metacognitively required the first author to be immersed in the data. In doing so, data extracts for each higher order category (strategy) were continually compared and contrasted, then narrowed down into representative lower order subcategories (processes). Narrowing of data required a clear description of subcategories (processes), which is provided in Table 2. The process of narrowing data required the first author to group extracts into subcategories, which initially caused some extracts to overlap into multiple subcategories. By looking for similarities and differences in the meanings between data extracts, the first author was able to reduce overlapping and ensure all data extracts were placed in singular subcategories.

To enhance trustworthiness, sample data extracts were examined by the second and third author at regular intervals, with any issues of contention discussed until a consensus of opinion was reached. The first author also discussed the process with a colleague, who was knowledgeable about coaching and trained in qualitative methodology, but blind to the objectives of the study (Krane et al. 1997; Wright, Trudel, and Culver 2007), on three separate 
Running head: APPROACHING AND SOLVING GAME PROBLEMS

occasions. The purpose of having 'critical friends' was to encourage discourse and reflexivity

to allow multiple interpretations of the data to be generated (Smith and McGannon, 2017).

248 Finally, the first author made reflexive notes immediately after each interview and throughout

249 the data analysis process to enhance the transparency of the choices and interpretations made

$250 \quad$ (Tracy, 2010).

$251 \quad$ Results

In the following sections, we outline how players utilised cognitive and metacognitive strategies and processes to solve game problems. Representative quotes are used to provide better appreciation of the context data were collected in, with exemplar data extracts for each category of learning strategy also presented in Table 2. To maintain anonymity, players are referred to by a unique letter.

\section{Cognitive Strategies and Processes}

\section{Rehearsal}

Three cognitive processes are associated with this strategy: copying, verbatim and repetition. In the first case, this was most evident in how players utilised copying as a process to start their reasoning during task scenarios, especially in relation to the club's preferred playing style. For example, this typically involved the player copying the coaches' tactical reasoning, which was supported by Player X when he explained how the team's playing style was a guide for decision making: it over this side where the space would be free.

In the case of using verbatim as a cognitive process, this tended to involve reference to technical or tactical language (e.g., 'bump up,' 'shuffle,' 'triangles,' 'play around'), formations 270 (in this case, 1-4-3-3) and team shape (e.g., high or low, wide or narrow), all of which were 
Running head: APPROACHING AND SOLVING GAME PROBLEMS

271

272

273

common to both the club's style of play and the coaching team's collective language. The use of verbatim was exemplified by Player A during simulation, when he described how 'he bumped up, and if he just...if he didn't bump then they would have still had the ball.'

Repetition was most commonly referred to during task scenarios. Examples of this occurred in relation to patterns of play (e.g., goalkeeper to centre back to centre midfielder when playing out from the back), as exemplified by Player F when he commented, 'yeah, because we work on it a lot in training. Playing out from the back. And like switching players over. We practice the same kind of patterns.'

\section{Organisation}

Two cognitive processes were linked to this strategy: grouping and categorizing. Categorizing was the most frequent process used, commonly alongside copying. This typically involved players summarising the options available in order to decide 'what next'. They would then use short cuts or tactical principles to decide on the most appropriate solution (e.g., play around the opponent if we cannot play through). When asked about the 'what next' when playing out from the back, Player F explained how playing it back to the centre back would create the opportunity to build play using the other side of the pitch, suggesting that 'if we played round, he can just lock it off and then we're back forcing it that way.'

The process of grouping explains how a group of people are interdependent; effective recognition and accommodation of this is another important aspect of metacognition. This is relevant to the tactical side of the game of soccer, where one player's actions have an effect on both their teammates and the opposition. However, this was the least frequent process under the strategy of organisation, although, during his knowledge audit, Player A explained that 'at first, I was going to carry on running, but then when I saw [teammate] and the other two coming, that's why I went inside.'

\section{Elaboration}


Running head: APPROACHING AND SOLVING GAME PROBLEMS

During the knowledge audit, the most frequent cognitive strategy was elaboration,

297 which includes three cognitive processes: mental note taking, mental images and self-

298 questioning. The most common process was mental note taking, where a player would typically

299 aim to remember certain pieces of information about the game, or people playing the game,

300 with the intention of using that information to inform future actions. Player L provided an example of how he used this process:

In the start of the game I was like...I just saw the player who was on me, it was just in the first like five minutes.

With regards to the use of mental images, evidence of approaching a problem by having

a clear representation of their intended goal in mind occurred most frequently in the task scenario and least often in the knowledge audit. Player S explained his thought process of how he was seeking to gain possession of the football in his defensive third and then intended on using possession once it was gained. He made reference to two mental images; the first when he was out of possession, when he said how he 'just had to keep running...just don't let my man run off me...try and run back as quick as I could, don't like stop', the second as he gained possession, when he said, 'just keep my eyes on the ball, don't lose it.'

The final process linked to elaboration was self-questioning. This was mostly evident

314 during the simulation and knowledge audit, and involved the player checking and challenging

315 their own thoughts in relation to the problem faced. In most cases, this process was evident

316 when their team had the ball, and they were concerned about losing possession. One example

317 was illustrated by Player U, when he asked himself 'what if I lose it? Is someone there to like

318 give me an option or to like help me recover?' In a further example, Player $\mathrm{X}$ asked himself,

319 'so what am I going to do next? ...because I beat the one person, then their number eight is 
Running head: APPROACHING AND SOLVING GAME PROBLEMS

320

going to start coming to press me, so then what am I going to do, like end-product, what am I going to do? What am I going to do in that situation?'

\section{Metacognitive Strategies and Processes}

\section{Strategy}

This metacognitive strategy consisted of three processes: selection of a cognitive strategy, execution of a cognitive strategy, and monitoring and control of a cognitive strategy. Notably, there were few examples of a player evidencing selection of a cognitive strategy in their problem-solving process. One of these examples, from Player X, involved the strategy selection of elaboration (mental note taking). He said:

I was thinking like they...throughout the whole game they went into that centre mid once, and I think it was because our team just dropped back fully. So, I thought they're going to hit it long, so I dropped off to see if they'd hit it long...we were pressing and then I decided to just drop off because I was looking out, I knew they just hit it long every time.

Importantly, at no stage during the interviews was there evidence of any player demonstrating an awareness of how a cognitive process was to be executed, nor how such processes were monitored and/or controlled. The implications of this for coaches and for coaching are important because, should a player's solution be tested and fail, it becomes difficult for them to determine the cause for failure. For example, if the player lacks reflection on their cognition, the cause of failure could be the choice or execution of a solution, or the deployment of an inappropriate and poorly executed cognitive process.

\section{Person}

Three processes were associated with this metacognitive strategy: knowledge of self, knowledge about others and knowledge of the universal. In the case of knowledge of self when solving problems, players tended to make reference to their physical qualities as a means to 
Running head: APPROACHING AND SOLVING GAME PROBLEMS

justify their intended actions. For example, Player D said, 'I know I can use my arms to keep him behind me...use strength, my strength to try and push him off the ball', while Player B suggested, 'my first priority is to get the ball under control and use my strength...so my arms and use my body to block out the defenders.'

Our results also show that knowledge of others would more often refer to knowledge of teammates than knowledge of opponents and tended to be used alongside the cognitive process of categorising. This was most evident in players' appreciation of their teammates' responsibilities when playing out from the back and how their ability to perform a role was interdependent on teammates' capabilities. This was evidenced by Player F: 'I think we have the ability to play round. Our goalkeeper's passing is very good, so we can play back to him and then do it that way.'

On many occasions, players exercised their knowledge of universal beliefs as a metacognitive process. One example of this was evident in the task scenario, when Player B noted that a youth academy footballer should be capable of executing a certain level of skill, suggesting that 'in situations like that...it's what you can individually do, he should...if I played in academy football for this team, he should be able to get past them if it's a one on one.’

\section{Task}

This metacognitive strategy was associated with two metacognitive processes: understanding how to approach learning and the impact of learning on task. During the task scenario, only three players evidenced an awareness of their learning approach, which in all cases were related to feelings and emotions. For example, Player I recognised that he performs better when he is not feeling too relaxed in possession, explaining that 'I sort of think when I'm playing out from the back, and in this instance, that I just need to relax, not overly relaxed though...take it round, like not slowly but relaxed I guess.' 
Running head: APPROACHING AND SOLVING GAME PROBLEMS

370

371

372

373

374

375

376

377

378

379

380

381

382

383

384

385

386

387

In most cases, when the impact of learning on task was evidenced, it was in conjunction with knowledge of others (universal). This meant that players' thought processes were often along the lines of how to make the task harder for their opponent, based upon what typically increases task difficulty in soccer. This was evidenced by Player S, who said 'if it's going to the line it's not going anywhere, it's not like he's cutting in the pitch and he's got the whole pitch to go, he's only got that much of the pitch to go, so try and block him, instead of getting a penalty, get a corner.'

There was just one example of a player who used impact of learning on task in relation to what they knew about the specific opponent. Even in this case, however, knowledge of the opponent was based only upon physical attributes. Player $\mathrm{Z}$ explained in the simulation, 'if he's faster than me, I'd tactical foul him, but if he's like...if I'm the same pace as him, I'd try and catch up to him and like force him onto the line.'

\section{Discussion}

The purpose of the current study was to examine how high-level youth soccer players approach and solve game problems, with a particular emphasis on the role of strategic understanding. The main benefit of the ACTA interview protocol we employed was to capture player thinking in order to differentiate between understanding (cognition) and deep understanding (metacognition).

\section{Having a solution is not enough!}

To develop deeper game understanding, our findings suggest there is a need to combine decision making training with explicit coaching to develop a range of cognitive processes (e.g., copying, grouping, mental note taking). In reality, however, coaching for understanding in the team sport literature is dominated by decision making and not combined with problem solving. Understanding team principles of play and tactics tend to be a focus for coaches (Lex et al. 2015; Tee, Ashford, and Piggott 2018), with little or no emphasis on how players think. For 
Running head: APPROACHING AND SOLVING GAME PROBLEMS

395

396

397

398

399

400

401

402

403

404

405

406

407

408

409

410

411

412

413

414

415

416

417

418

419

example, our findings show that players most frequently solve problems by using copying, grouping and categorizing. These processes typically related to soccer language, patterns of play, tactical concepts and positional connections between players, to guide decisions when problem solving. More sophisticated levels of thinking, such as elaborative cognitive processes (e.g., mental note taking, self-questioning and mental images) were utilised less, and use of analogies was not demonstrated at all from our participants.

Evidence of less sophisticated thinking processes is not necessarily a result of the players' age or stage of cognitive development. Children younger than those in our study have evidenced metacognition, albeit outside of a soccer context (Pino-Pasternak and Whitebread, 2010; Ricker and Richert, 2021; Veenman and Spanns, 2005; Wang et al. 2021; Weil et al. 2013). Instead, players seem merely to be using and demonstrating the soccer knowledge they have been taught by their coaches. Indeed, based upon the evidence from our study, it is unlikely the players we interviewed had been coached to learn and develop a range of cognitive processes, and most certainly not elaborative processes.

Yet, soccer is a complex task where there is a high volume of dynamic or conflicting contextual information. Players need to understand how a game context is layered with coordinated and patterned actions of an opposition team, individual or subgroup of players (Maquet and Kragba, 2015; Ashford, Abraham, and Poolton 2020). This would suggest that more sophisticated cognition is required (Weinstein and Mayer, 1986; MacIntyre et al. 2014), for players to outwit their opponent. We propose that players with a wider range of cognitive tools are better positioned to solve game problems. In other words, players capable of using elaboration (and not just rehearsal and organisation) have greater potential to outwit their opponent, even when the opponent is technically or physically superior. The aim of soccer (indeed any team sport) is to cause, sustain and enhance the stubbornness of a problem for the opponent. For coaches, the skill of developing players' cognitive processes is not straight 
Running head: APPROACHING AND SOLVING GAME PROBLEMS

420 forward and there is, therefore, no singular method to address quality of player thinking.

421 Instead, a multi-methods approach, we suggest, would provide greater opportunity and

422 possibility for players to become more aware and in control of their thought processes. Some

423 multi-methods include conversing with players on and off field about their performance and

424 learning goals, using regular reviews and debriefs, providing in time and on demand feedback,

425 watching and discussing soccer video clips, encouraging players to ask for help on specific

426 areas of performance, and encouraging players and coaches to share their thoughts and feelings.

427 Testing and tweaking

428 Our findings show that players seldom recall or demonstrate thoughts concerning how 429 they have planned to judge their own understanding of a solution (i.e., Did it work? How will

430 I know? If it didn't work, why not? If it did work, what does this mean for next time I am faced

431 with this problem?). If players were more proficient at learning how to deal with game

432 problems, data would evidence a strategic use of knowledge when approaching a problem. In

433 actuality, however, our findings show that player thinking is dominated by static contextual

434 information about team playing style, execution of skill, and roles and responsibilities of

435 playing positions. Players' consistent reference to static information during problem solving is

436 perhaps unsurprising, however. Research in formal coach education suggests minimal intent to

437 involve coaches in their own learning and in context specific situations (e.g., Cope et al. 2020).

438 Furthermore, coach education is largely dominated by the sport's technical and tactical content

439 knowledge, with limited integration of how players engage with learning strategies (Abrahams

440 and Collins, 2011). To clarify, if coaches are neither taught nor encouraged to learn about

441 methods to enhance the learning process of players, then it's likely that players will lack an

442 awareness of how they learn best.

443 During problem solving, judging the effectiveness of one's problem solving approach

444 suggests a player is being reflective during the learning process. However, metacognition is 


\section{Running head: APPROACHING AND SOLVING GAME PROBLEMS}

more than simply reflecting and, importantly, involves a strategic use of knowledge as problems are approached and solved. In soccer, which is based upon outwitting the opponent, knowing about the people playing the game (yourself, teammates and the opponent) should be major considerations. The current study offers limited evidence of players using their knowledge of others to shape their decision making. For example, thinking metacognitively about a problem to be solved requires an awareness of performance. This can include an awareness of capabilities, traits, strengths and weaknesses of self and others. In the context of a game, Levi and Jackson (2018) explain that performance is a dynamic 'contextual prior'. In other words, being aware of performance (and how it changes) provides the problem solver with information to guide decision making. Performance will change depending on circumstance (e.g., score status, momentum, coach instructions, weather), and so the extent to which a player is performing to their strengths, showing their weaknesses, or developing new traits, will not stay the same.

Strategic understanding of players and teams when learning to solve problems can be enhanced by encouraging metacognition, such as predicting, checking, monitoring, testing and controlling (Brown, 1987). For example, when seeking to learn about the performance of an opponent, a player might plan to monitor his/her skill set during the initial phase of a game. These are important ways of thinking for soccer players when problem solving, in an attempt to understand when and why a problem has (or hasn't) been solved. Players who have a deeper understanding of their problem solving approach are also, we suggest, better equipped to tweak how they solve the problem next time it is presented. As previously highlighted, our findings indicate that players rarely use or recall any strategy to monitor and evaluate how they solve problems. This is a crucial finding for coaches because, without preparing players and teams with meta-level thinking strategies, it is likely game problems will take longer to solve. 
Running head: APPROACHING AND SOLVING GAME PROBLEMS

469 Furthermore, a lack of evaluation and monitoring during problem solving will result in players

470 and teams who lack understanding of how to make progress in the game against an opponent.

471 When solving problems in soccer, controlling one's thought process to consider how

472 best to outwit the opponent will result in players and teams who can set stubborn problems

473 (and not just solve them). In the current study, it was uncommon for players to recall or

474 demonstrate how their use of knowledge would impact an opponent. Yet, soccer is considered

475 as a complex system where combinations of the game's rules and interactions between players,

476 form the basis of the problems to be solved (Grehaigne, Godbout, and Zeria 2011). Players

477 with a deep understanding are more aware of how the interdependency of these elements

478 develop as the game is being played (Gee, 2013). In other words, players who are thinking

479 metacognitively are capable of not just understanding a problem and solving it but can

480 influence the nature of a problem to make it less difficult to solve. In academic contexts the

481 ability to influence the difficulty of a problem is a common metacognitive skill (Ertmer and

482 Newby, 1996; McCrindle and Christensen, 1995). For soccer players and teams, the ability to

483 set a problem with a high degree of difficulty for the opponent is essential. Likewise, the ability

484 to deal with a problem by reducing its degree of difficulty is equally important.

485

486

487

488

489

490

491

492

493

\section{Implications for coaching practice}

For coaches to improve the depth of players' game understanding, and on what basis, the current study highlights the benefits of using mechanisms to make player thinking overt during naturalistic soccer related contexts. In short, that meta-level thinking and strategic understanding are important elements which should receive explicit focus from early in the development process. In line with previous studies in the domain of game understanding (cf. Richards, Collins, and Mascarenhas 2016), we suggest one key mechanism for promoting overt player thinking is 'slow off field' coaching. For example, coaching might include conversations between player and coach or player to player about game problems that have recently occurred. 
Running head: APPROACHING AND SOLVING GAME PROBLEMS

494 These conversations might include visual stimuli such as video footage, a tactical diagram or 495 tactic board. The findings of the current study offer an important contribution to Richards et

496 al. (2016); namely, the focus of conversations should not just be limited to solutions for

497 problems. Instead, conversations ought to extract and reflect on use of cognitive process and

498 strategy. We recommend the supporting probes in Table 1 (adapted from Militello and Hutton,

499 1998) as a useful start point for coaches to utilise for off field coaching conversations. This

500 type of questioning could be integrated into coach education qualifications as a core coaching

501 skill and framed to coaches as a tool for developing players depth of game understanding.

502 Notably, from the coach perspective, recent developments have stressed the importance of

503 considering alternative approaches, aimed at building deeper understanding of the process

504 (e.g., Collins \& Collins, 2020). A similar approach can be used with players and developed in coaches as a personal and coaching tool.

Nevertheless, coaching for cognitive process and strategy should not be confined to

507 'slow off field' situations. Nor should coaching for cognition be used only after the problem

508 has passed; typically, how coaching teams often approach analysis and reflection on

509 performance (Wright, Carling, and Collins 2014). Instead, we suggest that practicing cognitive

510 process and strategy must also happen during 'fast on field' situations (Richards, Collins, and

511 Mascarenhas 2016), or in other words, in real time and as it is happening. Real-time context is

512 important for players to learn how to test and tweak their thinking, as the problem is unfolding.

513 Clearly, coach education has a role to play with prompting coaches to develop how

514 players think and not just what they think. One suggestion is for coach educators and coach

515 developers to be aware of and to fully understand new approaches emerging which may be

516 useful. Despite metacognition and the role of strategic understanding for team sport being

517 limited in both theory and practice, recent literature has recognised how a Digital Video Games

518 Approach (DVGA) (Price et al. 2017) can develop players' metacognitive game skills 
Running head: APPROACHING AND SOLVING GAME PROBLEMS

519 (Stephanou and Karamountzos, 2020). A DVGA is underpinned by five pedagogical principles,

520 which act in harmony to guide how a practice is designed and coached. The five principles are

521 intended to act as mechanisms which explicitly ask players to think about how they think about

522 playing the game, as they play it. For example, the principle of 'pausing' requires the players

523 themselves to decide when to pause play and with what and how they would like to be

524 supported or challenged (see Price et al. [2017] for a detailed overview of the five pedagogical 525 principles of a DVGA).

526 The benefits of making player thinking overt on or off field and in fast or slow 527 situations, will provide coaches with the opportunity to understand how players arrive at a

528 solution. Importantly, making player thinking overt during problem solving will show to what

529 extent they engage with cognitive strategy and the ways in which they control what knowledge

530 to use and when. We hope this will re-position how team games coaches perceive their role in

531 how players think about how they play the game. Our final message for coaches and coaching

532 practice is to consider the value in coaching for the problem-solving process itself, and not just

533 coaching to find and execute the solution to a problem.

\section{Acknowledgements}

535 The author(s) would like to thank the soccer club and associated coaches for supporting with

536 the logistics of this study, in addition to the players for taking part.

\section{Declaration of Interest}

538 No potential conflict of interest was reported by the author(s).

539

540

541

542 
Running head: APPROACHING AND SOLVING GAME PROBLEMS

544

545

546

547

548

549

550

551

552

553

554

555

556

557

558

559

560

561

562

563

564

565

566

567

568

\section{References}

Abraham, A., \& Collins, D. (2011). Taking the next step: Ways forward for coaching science. Quest, 63(4): 366-384. doi:10.1080/00336297. 2011.10483687

Almond, L. (2015). Rethinking teaching games for understanding. Ágora Para La Educación Física Y El Deporte, 17(1): 15-25.

Ashford, M., Abraham, A., \& Poolton, J. (2020). A communal language for decision making in team invasion sports. International Sport Coaching Journal, 8(1): 122-129. doi.org/10.1123/iscj.2019-0062

Australian Sports Commission. (1996). Game sense: Perceptions and actions research report. Belconnen, ACT: Author.

Bengtsson, M. (2016). How to plan and perform a qualitative study using content analysis. Nursing Plus Open, 2: 8-14.

Brown, A. L. (1987). Metacognition, executive control, self-regulation, and other more mysterious mechanisms. In F. Weinert \& R. Kluwe (Eds.), Metacognition, motivation and understanding (pp. 393-451). Erlbaum.

Collins, D., \& Collins, L. (2020). Developing coaches' professional judgement and decision making: Using the 'Big 5'. Journal of Sports Sciences. doi.org/10.1080/02640414.2020.1809053

Colins, R., Collins, D., \& Carson, H. (2021). Muscular collision chess: a qualitative exploration of the role and development of cognition, understanding, and knowledge in elite-level decision making. International Journal of Sport and Exercise Psychology. doi.org/10.1080/1612197X.2021.1907768

Cope, E., Cushion, C.J., Harvey, S., \& Partington, M. (2020). Investigating the impact of a Freirean informed coach education programme. Physical Education and Sport Pedagogy, 26(1): 65-78. 
Running head: APPROACHING AND SOLVING GAME PROBLEMS

den Duyn, N. (1997). Game sense: Developing thinking players - a presenter's guide and workbook. Australian Sorts Commission.

Ertmer, P., \& Newby, T. (1996). The expert learner: Strategic, self- regulated and reflective. Instructional Science, 24(1): 1-24.

Flavell, J. H. (1979). Metacognition and cognitive monitoring. American Psychologist, 34(10): 906-911.

Gee, J. P. (2013). Good video games and learning. New York, NY: Peter Lang Publishing Inc.

Gier, J., Aksum, K.M., Pederson, D.M., Walvekar, A., Trivedi, A., McCall, A., Ivarsson, A., \& Priestley, D. (2020). Scanning, contextual factors and association with performance in English Premier League footballers: An investigation across a season. Frontiers in Psychology. doi.org/10.3389/fpsyg.2020.553813

Grehaigne, J. F., \& Godbout, P. (1995). Tactical knowledge in team sports from a constructivist and cognitivist perspective. Quest, 47: 490-505.

Grehaigne, J. F., Godbout, P., \& Zerai, Y.Z. (2011). How the "rapport de forces" evolves in a soccer match: the dynamics of collective decisions in a complex system. Revisita de Psicologia del Deporte, 20(2): 747-765.

Jacobs, J. E., \& Paris, S. G. (1987). Childrens metacognition about reading - Issues in definition, measurement, and instruction. Educational Psychologist, 22(3-4): 255-278.

Javadi, M., \& Zarea, K. (2016). Understanding thematic analysis and its pitfalls. Journal of Client Care: An International Nursing Journal, 1(1): 34-40.

Johnstone, D., \& Morrison, B.W. (2016). The application of naturalistic decision-making techniques to explore cue use in rugby league play makers. Journal of Cognitive Engineering and Decision Making, 10(4): 391-410. 
Running head: APPROACHING AND SOLVING GAME PROBLEMS

592 Kannekens, R., Elferink-Gemser, M. T., \& Visscher, C. (2009). Tactical skills of world-class youth soccer teams. Journal of Sports Sciences, 27(8): 807-812.

594

Kannekens, R., Elferink-Gemser, M. T., \& Visscher, C. (2011). Positioning and deciding: Key factors for talent development in soccer. Scandinavian Journal of Medicine and Science in Sports, 21: 846-852.

Kinrade, N. P., Jackson, R. C., \& Ashford, K. J. (2015). Reinvestment, task complexity and decision making under pressure in basketball. Psychology of Sport and Exercise, 20: $11-19$.

Klein, G. A. (2008). A recognition-primed decision (RPD) model of rapid decision making. In G. A. Klein, J. Orasanu, R. Calderwood, \& C. E. Zsambok, (Eds.), Decision making in action: Models and methods (pp. 138-147). Ablex.

Krane, V., Anderson, M.B., \& Strean, W.B. (1997). Issues of qualitative research methods and presentation. Journal of Sport and Exercise Psychology, 19: 213-218.

Levi, H. R., \& Jackson, R. C. (2018). Contextual factors influencing decision making: Perceptions of professional soccer players. Psychology of Sport and Exercise, 37: 1925.

Lex, H., Essig, K., Knoblauch, A., \& Schack, T. (2015). Cognitive representations and cognitive processing of team-specific tactics in soccer. PLOS ONE, 10, e0118219. doi.org/10.1371/journal. pone.0118219

McCrindle, A. R., \& Christensen, C. A. (1995). The impact of learning journals on metacognitive and cognitive processes and learning performance. Learning and Instruction, 5: 167-185.

MacIntyre, T. E., Igou, E. R., Campbell, M. J., Moran, A. P. P., \& Matthews, J. (2014). Metacognition and action: a new pathway to understanding social and cognitive aspects of expertise in sport. Frontiers in Psychology, 5(115): 1-12. 
Running head: APPROACHING AND SOLVING GAME PROBLEMS

617

618

619

620

621

622

623

624

625

626

627

628

629

630

631

632

633

634

635

636

637

638

639

640

McPherson, S. L. (1999). Tactical differences in problem representations and solutions in collegiate varsity and beginner women tennis players. Research Quarterly for Exercise Sport, 70: 369-384.

McPherson, S. L. (2000). Expert-novice differences in planning strategies during collegiate singles tennis competition. Journal of Sport and Exercise Psychology, 22: 39-62.

Militello, L. G., \& Hutton, R. J. B. (1998). Applied cognitive task analysis (ACTA): A practitioner's toolkit for understanding cognitive task demands. Ergonomics, 41(11): 1618-1641.

Nevett, M. E., \& French, K.E. (1997). The development of sport-specific planning, rehearsal, and updating of plans during defensive youth baseball game performance. Research Quarterly for Exercise Sport, 68: 203- 214.

Pill, S., \& Hyndman, B. (2018). Gestalt psychological principles in developing meaningful understanding of games and sport in physical education. Journal of Teaching in Physical Education, 37(4): 322-329.

Pino-Pasternek, D., \& Whitebread, D. (2010). The role of parenting in children's self-regulated learning. Educational Research Review, 5: 220-242.

Price, A., Collins, D., Stoszkowski, J., \& Pill, S. (2017). Learning to play soccer: Lessons on meta-cognition from video game design. Quest, 70 (3): 321-333.

Price, A., Collins, D., Stoszkowski, J., \& Pill, S. (2019). Coaching games: Comparisons and contrasts. International Sport Coaching Journal, 6(1): 126-131.

Price, A., Collins, D., Stoszkowski, J., \& Pill, S. (2020). Strategic understandings: An investigation of professional academy youth soccer coaches' interpretation, knowledge, and application of game strategies. International Sport Coaching Journal, 7(2): 151162. 
Running head: APPROACHING AND SOLVING GAME PROBLEMS

641 Richards, P., Collins, D., \& Mascarenhas, D. R. D. (2016). Developing team decision making: 642 a holistic framework integrating both on-field and off-field pedagogical coaching processes. Sports Coaching Review, 6: 57-75.

644

Ricker, A.A., \& Richert, R, A. (2021). Digital gaming and metacognition in middle childhood.

646

648

649

650

651

652

653

654

655

656

657

658

659

660

661

662

663

664

665 Computers in Human Behavior, 115: 106583.

Roca, A., Williams, M., \& Ford, P. R. (2012). Developmental activities and the acquisition of superior anticipation and decision making in soccer players, Journal of Sports Sciences, 30(15): 1643-1652.

Roca, A., Ford, P. R., \& Memmert, D. (2018). Creative decision making and visual search behavior in skilled soccer players. PLoS ONE 13(7): e0199381. doi.org/10.1371/journal.pone.0199381

Roca, A., Ford, P. R., \& Memmert, D. (2020). Perceptual-cognitive processes underlying creative expert performance in soccer. Psychological Research. doi.org/10.1007/s00426-020-01320-5

Smith, B., \& McGannon, K. R., (2017). Developing rigor in qualitative research: Problems and opportunities within sport and exercise psychology, International Review of Sport and Exercise Psychology, 11: 101-121.

Stratton, G., Reilly, T., Williams, M. A., \& Richardson, D. (2004). Youth soccer: From science to performance. Routledge.

Stephanou, G., \& Karamountzos, D. (2020). Enhancing students' metacognitive knowledge, metacognitive regulation and performance in Physical Education via TGfU. Research in Psychology and Behavioural Sciences, 8(1): 1-10.

Tee, J. C., Ashford, M., \& Piggott, D. (2018). A tactical periodization approach for rugby union. Strength and Conditioning Journal, 40(5): 1-13.

Tracy, S. J. (2010). Qualitative quality: Eight 'big-tent' criteria for excellent qualitative 
Running head: APPROACHING AND SOLVING GAME PROBLEMS

666 research. Qualitative Inquiry, 16: 837-851.

667

668

669

670

671

672

673

674

675

676

677

678

679

680

681

682

683

684

685

686

687

688

689

Wang, M.T., Binning, K.R., Toro, J.D., Qin, Z. \& Zepeda, C.D. (2021). Skill, Thrill, and Will: The Role of Metacognition, Interest, and Self-Control in Predicting Student Engagement in Mathematics Learning Over Time. doi.org/10.1111/cdev.13531

Weil, L.G., Fleming, S.M., Dumontheil, I., Kilford, E.J., Weil, S.M., Rees, G., Dolan, R.J. \& Blakemore, S.J. (2013). The development of metacognitive ability in adolescence. Consciousness and Cognition, 22: 264-271.

Wein, H. (2004). Developing game intelligence in soccer. Readswain Inc.

Weinstein, C. E., \& Mayer, R. E. (1986). The teaching of learning strategies. In M.C. Wittrock (Ed.), Handbook of research on teaching (3rd edn.) (pp. 315-327). Macmillan.

Weinstein, C. E., \& Van Mater Stone, G. (1993). Broadening our conception of general education: The self-regulated learner. New Directions for Community Colleges, 21(1): $31-39$.

Williams, M., \& Davids, K. (1995). Declarative knowledge in sport: A by-product of experience or a characteristic of expertise. Journal of Sport and Exercise Psychology, 17: 259-275.

Wright, C., Carling, C., \& Colins, D. (2014). The wider context of performance analysis and its application in the football coaching process. International Journal of Performance Analysis in Sport, 14(3): 709-733.

Wright, T., Trudel, P., \& Culver, D. (2007). Learning how to coach: The different learning situations reported by youth ice hockey coaches. Physical Education and Sport Pedagogy, 12(2): 127-124.

Veenman, M.V.J., \& Spanns, M.A. (2005). Relation between intellectual and metacognitive skills: Age and task differences. Learning and Individual Differences, 15: 159-176. 
Running head: APPROACHING AND SOLVING GAME PROBLEMS

690 Vaeyens, R., Lenoir, M., Williams, A. M., \& Philippaerts, R. M. (2011). Mechanisms 691 underpinning successful decision making in skilled youth soccer players: An analysis

692 of verbal reports. International Research of Science and Soccer, Chapter 4: 21-28.

693

694

695

696

697

698

699

700

701

702

703

704

705

706

707

708

709

710

711

712

713 
Running head: APPROACHING AND SOLVING GAME PROBLEMS

Table 1. Supporting Probes for ACTA Interviews (adapted from Militello \& Hutton, 1998)

\begin{tabular}{ll}
\hline ACTA Protocol & \multicolumn{1}{c}{ Probes } \\
\hline Task Scenario & How would your team play here, and why? \\
& What is your role in this, and why? \\
Knowledge Audit $\quad$ Past and Future: & Do you recall reading this situation? \\
& Do you recall feeling like you knew exactly how this situation arisen? \\
& Do you recall feeling like you knew where this situation was going? \\
& Big Picture: \\
& Can you tell me what is important for the team in this situation? \\
& What are the major elements you need to know and keep track of?
\end{tabular}

Opportunities//Improvising:

Can you recall making a decision to improvise in this situation?

Can you recall noticing an opportunity to perform better?

Self-Monitoring:

In this situation, did you realise you needed to change what you were doing in order to achieve the desired outcome?

Job Smart:

When you acted in this situation, were there any ways in which you achieved more with less effort?

Simulation What do you think is going on here?

What is your assessment of this situation in this moment?

What pieces of information led you to this assessment, and actions?

As the player in this situation, what actions, if any, would you take in this moment?

What errors would an inexperienced player likely make in this situation? 
Table 2. Categories of Learning Strategies (Weinstein \& Mayer, 1986)

\begin{tabular}{|c|c|c|c|c|c|}
\hline Cognitive Strategy & Cognitive Processes & Exemplar Data Extract & $\begin{array}{l}\text { Meta-cognitive } \\
\text { Strategy }\end{array}$ & $\begin{array}{l}\text { Meta-cognitive } \\
\text { Processes }\end{array}$ & Exemplar Data Extract \\
\hline \multirow[t]{3}{*}{ Rehearsal } & $\begin{array}{l}\text { copying: reproducing } \\
\text { something }\end{array}$ & $\begin{array}{l}\text { Use the width. And make sure you } \\
\text { have a diamond structure as well. }\end{array}$ & Strategy & $\begin{array}{l}\text { selection of cognitive } \\
\text { strategy }\end{array}$ & $\begin{array}{l}\text { I was sure I was going to get the ball } \\
\text { but just in case, I sort of had in my } \\
\text { mind, that I would hold on to the ball } \\
\text { for longer to see if his teammate } \\
\text { came and doubled up on me. }\end{array}$ \\
\hline & $\begin{array}{l}\text { repetition: repeating } \\
\text { something }\end{array}$ & $\begin{array}{l}\text { We always play to one of our centre } \\
\text { backs from goal kick. }\end{array}$ & & $\begin{array}{l}\text { execution of cognitive } \\
\text { strategy }\end{array}$ & $\begin{array}{l}\text { So, I thought, I'm just going to do } \\
\text { what he did, just get the ball and } \\
\text { shoot. }\end{array}$ \\
\hline & $\begin{array}{l}\text { verbatim: quoting } \\
\text { words and phrases }\end{array}$ & $\begin{array}{l}\text { When the ball is here, we create } \\
\text { triangles and shuffle up the pitch. }\end{array}$ & & & \\
\hline Organisation & $\begin{array}{l}\text { grouping: ordering } \\
\text { information by } \\
\text { connecting things } \\
\text { together }\end{array}$ & $\begin{array}{l}\text { I was looking for one of the } \\
\text { midfielders to bounce off. But then } \\
\text { there was none around, so then I } \\
\text { just decided to clip it in. }\end{array}$ & & $\begin{array}{l}\text { monitoring \& control of } \\
\text { cognitive strategy }\end{array}$ & $\begin{array}{l}\text { I needed to have another look at his } \\
\text { body shape next time he got on the } \\
\text { ball... I don't see it properly the first } \\
\text { time. Then I could see if it worked or } \\
\text { not. }\end{array}$ \\
\hline
\end{tabular}




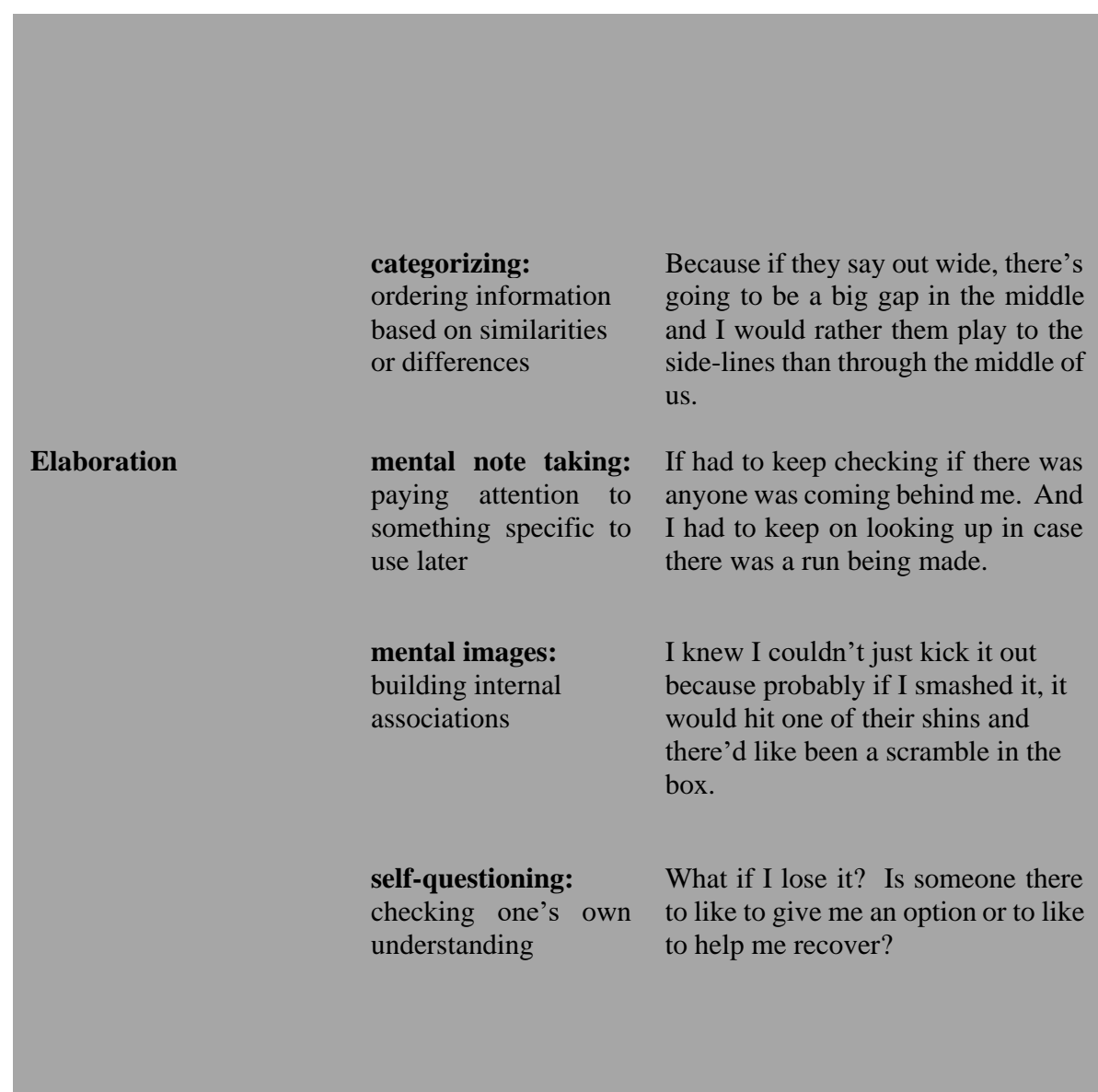

\begin{tabular}{|c|c|c|}
\hline \multirow[t]{3}{*}{ Person } & $\begin{array}{l}\text { self-knowledge } \quad \text { (my } \\
\text { capabilities) }\end{array}$ & $\begin{array}{l}\text { I'm a really composed player and } \\
\text { I'm really relaxed, sometimes too } \\
\text { relaxed on the ball. That's why I } \\
\text { dropped deep and asked for it. }\end{array}$ \\
\hline & $\begin{array}{l}\text { knowledge about others } \\
\text { (teammates' and } \\
\text { opposition capabilities) }\end{array}$ & $\begin{array}{l}\text { Because he's left-footed I think, so } \\
\text { that's on his weak foot as well. If he } \\
\text { drops right the way down there. It } \\
\text { would cause a problem for him. }\end{array}$ \\
\hline & $\begin{array}{l}\text { knowledge of the } \\
\text { universal (beliefs about all } \\
\text { human thinking) }\end{array}$ & $\begin{array}{l}\text { In situations like that, it's what you } \\
\text { can individually. He should be able } \\
\text { to get past them if it's a one on one. }\end{array}$ \\
\hline \multirow[t]{2}{*}{ Task } & $\begin{array}{l}\text { understanding how to } \\
\text { approach learning }\end{array}$ & $\begin{array}{l}\text { I was getting quite frustrated } \\
\text { because I wasn't getting the ball and } \\
\text { I wanted to impress the coaches. }\end{array}$ \\
\hline & $\begin{array}{l}\text { recognition of how } \\
\text { learning impacts ease or } \\
\text { difficulty of task }\end{array}$ & $\begin{array}{l}\text { Because like say he's pressing and } \\
\text { he's coming towards me, it's a } \\
\text { harder pass for him to go there, but } \\
\text { if he drops his feet down like on the } \\
\text { line there, it's an easier pass. }\end{array}$ \\
\hline
\end{tabular}

Note: the authors removed the category of 'analogies' from this table because it contained no data. 